\title{
浅析现代建筑中的室内陈设设计
}

\author{
王晶 \\ 内蒙古乌海职业技术学院 \\ DOI:10.32629/btr.v1i4.1584
}

[摘 要] 社会在发展, 时代在进步,最近几年以来人民生活水平得到了很大改善, 这使得人类对物质和精神上的追求也有了明 显提高,人们开始越来越关注自己的生活环境, 其中室内环境也受到了高度关注。如何营造富有特色且宜居的室内环境成为一 个重要研究方向。在室内设计中, “轻装修, 重装饰”, 体现本土文化及个性化空间成为主流设计理念, 运用陈设原则巧妙搭配陈 设元素带给人身心的舒适才是陈设设计的重点。本文对现代室内设计中的城市艺术做了深入研究,阐述了陈设艺术的概念等, 并且深入分析了陈设艺术在室内装饰设计中的作用。

[关键词] 室内设计；陈设艺术；分类；作用

\section{1 室内设计中陈设艺术的概念}

室内陈设艺术相较于其他艺术创作来说具有很大区别, 室内陈设艺术由于空间问题会受到一定的环境制约, 但是在 整个设计过程中仍然要保持艺术与环境达到和谐统一。在进 行陈设设计之前, 设计这个首先要做的就是明确室内设计和 陈设艺术设计之间的关系, 对于室内装饰、室内装潢设计、 室内布置、室内物品摆设等的概念都要明确区分开来, 同时 也要具备一定的绘画基础, 装饰基础以及设计基础。由此可 见, 室内陈设设计作品必须要具备一定的深度和难度。对于 室内设计来说, 室内陈设艺术设计占据重要位置, 二者之间 有着密切联系, 存在不同点的同时也有着很多相同点。室内 設计是一个广义上的概念, 而陈设艺术设计则是在室内设计 的基础上进行更加具体的细致的工作, 主要目的是增加室内 空间的实用性和艺术感。

\section{2 陈设设计是室内设计的灵魂要素}

室内设计是对空间组织规划, 并对各个界面进行设计, 再根据其硬质装饰设计, 搭配合理的色彩, 照明, 材质及家具 等, 从而创造出兼具实用及美观的空间环境。室内设计分为 硬装设计和软装设计两大部分, 其中, 陈设设计就是室内装 饰设计的核心及灵魂要素, 是营造功能合理, 风格独特的室 内氛围的主要手段, 陈设设计与室内环境设计是整体与局部 的关系。

\section{3 室内陈设的分类}

在进行现代室内设计的过程中, 陈设艺术主要包括实用 陈设品、装饰陈设品、陈设织物三种形式。具体内容如下:

3.1 实用陈设品

在生活中人们经常用到的日用品称之为实用陈设品, 其 中包括书籍杂志、文体用品、家用电器、生活器具等。最具 代表性的就是陶瓷制品, 在生活中十分常见, 陶瓷制品既可 以当作艺术装饰品使用, 同时也可以将其作为生活用品, 即 具备实用价值, 又具备观赏价值。

\section{2 装饰陈设品}

只具有观赏价值, 而不具备使用价值的陈设品称之为装
饰陈设品。例如纪念品、工艺品以及观赏性植物等都属于装 饰陈设品。

\section{3 室内陈设中的织物}

植物的特点是具有一定的柔软性和亲切感, 在室内设计 中陈设织物可以在很大程度上提高室内空间的层次感和文 化风情, 利用织物对空间进行分隔处理, 可以使打造出一种 “隔而不断”、意境幽深的空间效果。

\section{4 陈设设计的原则}

4. 1 协调统一原则

设计需要统一协调, 陈设设计也是如此, 如何利用织物、 家具、陈设艺术品、绿化、照明等要素营造空间, 使各陈设 品在造型、色彩、材质、风格等方面达到最优组合, 呈现协 调统一, 才是室内设计完美与否的关键。

首先, 次要部位从属主要部位。在陈设设计中, 结合设计 最初定位风格, 把握风格元素, 从色彩, 造型, 质感, 数量及体 量感等方面通过重点区域的元素塑造与附属区域的相互配 合, 营造空间整体格调; 如地中海风格陈设, 应重点把握蓝白 色调的运用, 拱券造型的使用, 自然质朴材质的配合; 在现代 简约风格的陈设设计中, 应运用黑白灰色调, 直线简洁造型; 在东南亚风格的陈设设计时, 则注重撞色织物的运用, 绚烂 壁纸的使用以及自然材质的使用等。总之, 在空间塑造时突 出主体部分, 结合各部分的点缀作用, 形成层次感较强富有 格调的室内空间。

\section{2 均衡而富有变化}

均衡而有变化是所有设计必须遵循的原则, 运用到室内 陈设设计中是指室内的软装饰元素从色彩, 形态及材质等方 面构成一种视觉上的平衡美感。在室内陈设设计中常用轴对 称布置, 有时也采用中心对称的陈设形式, 两种对称均为均 衡的表现手法。除此以外, 为营造一种富有变幻而稳定的形 式美感, 在陈设时, 还需遵循节奏与渐变, 空间感的构成准则, 同时同构, 共生, 异变, 放射, 渐变等多种平面构图形式也可 借鉴。

4.3 为人服务, 体现人情味 
设计就像一架天平, 在美观与实用之间寻求平衡点。陈 设设计为人提供视觉上的美感,生活上的舒适感。从使用者 角度出发, 进行设计, 真正做到为人服务的设计准则。陈设设 计是技术更是艺术, 在设计中要符合人机工程学的基本要 求。在界面设计中, 家具平面布局时应合理把握家具尺度, 符合人体使用需求。如预留空间通行距离, 保证使用者可顺 利通过, 在客厅设计时, 注意沙发与电视背景墙距离, 保证人 坐沙发上看电视的最佳视距。再如, 在博物馆陈列摆放展品 时, 根据人的视觉行为及参观心理, 合理恰当进行陈列。环境 心理学是设计中的重要学科, 如何结合人在不同环境中的心 理感受是陈设设计是否为人服务的重要衡量标准。不同的色 彩有其色彩语言, 不同的使用人群也有色彩喜好。在陈设设 计时结合不同空间环境及使用者需求, 合理配色, 营造适宜 的环境氛围, 满足使用者的身心需求。符合大众审美, 又做到 同中有异, 个性化的设计才是设计的高级阶段。

\section{5 室内陈设艺术在现代室内设计中的作用}

5.1 打造意境, 烘托室内气氛

意境指的是空间环境所表达的主题, 而气氛则指的是空 间给人们的感觉。意境相较于气氛来说更容易被人们感受到, 还能让人们在一定的环境下进行联想, 从而体会到更好的精 神享受。例如人民大会堂顶部的灯饰设计, 主要以大五角星 为中心, 周围散布着很多灯, 打造出了一种满天星的感觉, 这 很容易让人们联想到全国人民在共产党的领导下团结一致, 不断进取, 良好的突出了 “全国人民大团结” 的主题, 气氛分 外庄严, 肃穆。合理的应用地毯、窝饰等织物可以有效缓解 天花板过高造成的空旷感, 从而营造出一种温馨的气氛。

\section{2 营造人性化空间氛围}

现代建筑多采用钢筋水泥筑成, 冷硬的现代装修材料充 斥在我们生活当中, 人们对充满人情味的室内环境更加渴望, 巧妙利用绿化, 家具, 植物等室内柔性装饰, 打造富有自然及 生活气息的室内氛围是未来室内设计发展必经之路。不同的 空间环境对人有不同的感染力, 当人们身处一个明度较高的 空间时, 感觉明快活泼。明度较低的空间环境, 则使人感到庄 严抑或压抑。因此, 合理利用设计形态、色彩、材质、灯光 等因素构成与空间属性相一致的人性化空间氛围十分重要。 在儿童房间设计时多用明度较高的彩色系列。在以女装为主 的专卖店设计时则多用粉色、淡紫色等女性化的柔性装饰及 色彩, 在电子产品的展示店则以表现高科技的现代化材料及 装饰。总之, 合理搭配陈设设计的色彩, 材质, 灯光等多种构 成要素, 从人性化角度出发, 营造宜居、宜人环境。
5.3 增加艺术感, 深化空间涵义

舒适美观是室内空间设计的基础要素。不同的空间设计 就不同的要求, 对于一些具有特殊要求的空间, 在设计过程 中一定要保持空间内涵。例如重庆中美合作所展览馆烈士墓 地下展厅等一些具有纪念性意义的建筑空间, 整个空间呈圆 形, 顶部设有圆形天窗, 周围墙壁描绘这生动形象的大型壁 画, 光线可以通过天窗奔泄而下, 打造出一副震撼人心的画 面。不仅增加了艺术感, 也在一定程度上深化了空间含义。

\section{4 展现艺术性, 情感的真实写照}

室内陈设是使用者个性的体现, 是其情感及生活的真实 表达。“装修可以复制, 装饰是无法复制的, 让家成为你的家”, 这是瑞丽家居杂志中对陈设设计的定位。室内陈设按照其功 能属性划分, 可以分为装饰性陈设和实用性陈设。装饰性陈 设本无实际实用用途, 因其特殊纪念意义, 陈设效应或艺术 价值而在室内设计中得以应用。实用性装饰, 主要是实用性 能, 有时也因色彩艳丽、造型有趣而起到装饰美化的作用, 如造型独特的玻璃果盘, 与室内风格相统一的各式台灯, 装 帧精美的书籍等。因此, 室内陈设本身就是艺术品, 是室内使 用者的情感传达。

\section{6 结语}

综上所述, 陈设艺术涉及到的内容较为广泛, 形式多种 多样。对于室内空间设计来说, 陈设品发挥着重要作用, 对其 进行合理的选择和摆放不仅可以美化室内空间环境, 也能充 份的体现出人们的文化修养和整体品位, 既满足了对舒适和 健康的需求, 更有益于人们的身心健康。对此, 设计师在进行 室内设计的过程中, 必须要根据空间的使用功能和整体环境 合理选择陈设品, 搭配得当, 充分发挥其积极作用, 争取创造 出更加舒适健康、极具艺术感的人性化空间。

\section{[参考文献]}

[1]乔国玲.陈设设计课程的教学与实践探索 [J]. 装 饰,2014,(11):48-49.

[2] 魏婷. 现代室内设计中陈设艺术的应用[J].美术教育 研究,2015,(08):57.

[3]朱晓娟.浅析陈设艺术在现代室内设计中的应用 [J]. 美术教育研究,2015,(19):32。

[4]王媛.浅谈陈设艺术在现代室内设计中的作用 [J].名 作欣赏,2013,(08):53-54.

[5]康天驰. 室内陈设艺术的设计与应用 [J]. 居 舍,2018,(25):68-69. 